\title{
DOSSIÊ: \\ Práticas Educativas e Formação Docente: ressignificando metodologias e saberes
}

A docência em tempos pandêmicos chamou-nos à coletividade para reunir trabalhos que mostram como as metodologias e as práticas educativas estão sendo pensadas e organizadas pelos professores, enquanto atravessam esse período e ressignificam os fazeres na docência. A formação, como espaço que acreditamos para a docência, foi provocada a se recriar em sua iniciação à docência ou em serviço. $A$ universidade, em sua responsabilidade formadora, lançou-se a investigar: o campo educacional está sempre se voltando para si em uma formação investigativa, que se constitui continuada e que se refaz ao longo do tempo com as experiências que colecionamos. Nossos repertórios de trabalho, de arte e de lazer, dizem das condições funcionais que nos fazem professores e proporcionam condições criadoras e que sustentam os fazeres metodológicos, imaginativos e investigativos se multiplicarem, tornando-se saberes importantes que dizem da nossa profissão.

Passamos a rever e a ressignificar as metodologias e os saberes de um fazer docente para adequar à condição de ensino e de aprendizagem remota, híbrida ou presencial com cuidados sanitários. O desafio em compreender e organizar os fazeres e saberes docentes levou a consequências que precisam ser mais bem discutidas e reconhecidas. Este dossiê traz esta proposta e tenta cumprir este chamado. Poderemos olhar para práticas e investigações que tentaram redesenhar as configurações de uma educação para os cenários vindouros. Aqui também buscamos congregar estudos e pesquisas que têm se debruçado sobre as práticas educativas e de formação docente, procurando conhecer as metodologias que educadores/ pesquisadores têm organizado nos seus fazeres e saberes, bem como as ressignificações impostas pelo momento histórico-cultural vivido na contemporaneidade.

Está convidativo passear pelos artigos aqui apresentados, muitos deles resultantes de pesquisas que levam a pensar sobre os processos educativos em diferentes metodologias investigativas e/ou processos de produção de conhecimentos, decorrentes dos fazeres e saberes docentes. As consequências da pandemia convocam-nos a persistir em metodologias que sejam inclusivas em um espectro ainda maior. A sala de aula redefiniu parâmetros, ressignificou os estágios obrigatórios e ratificou a prática acompanhada durante a formação, que transita entre a escola e a universidade. Ampliamos as pesquisas, olhando a partir de parcerias internacionais e os aprendizados freirianos. Novos espaços de formação inicial passam a compor o cenário das instituições formadoras: um olhar cuidadoso para a sua avaliação é imprescindível, dada a incumbência que a educação desempenha socialmente.

Entre a virtualização experimentada durante todo o transcurso pandêmico e a lembrança da presencialidade, o corpo quase esquecido reclama seu espaço. Qual valoração lhe daremos, posto que está sempre conosco? Qual seu espaço nas metodologias ressignificadas? Práticas de um tempo de presencialidade e remotas, revisadas em processos autoformativos reavaliam o trajeto docente profissional. $\mathrm{E}$ a educação inclusiva reafirma-se dentro dos espaços de formação: o ensino, a pesquisa e a extensão são 
lugares para fortalecer vínculos entre os espaços que se ocupam da docência. Assim, a seguir apresentamos um pouco mais de cada artigo que compõe este dossiê, entregando-o ao estudo de práticas e saberes docentes.

As autoras Tásia Fernanda Wisch e Cláudia Terra do Nascimento Paz trazem por cenário a sala de aula regular para pensar, problematizando o Ser Professor na Perspectiva Inclusiva: saberes, fazeres e compromissos em uma tríade formativa. A educação inclusiva reveste-se de conceitos aqui tratados na perspectiva da formação. Por fim, apresentam o protagonismo de uma docência que tem por foco a aprendizagem de todos os estudantes em uma tríade formativa que pressupõe a relação entre saberes, fazeres e compromissos para a construção permanente do profissional inclusivo. $O$ estudo leva-nos a perceber que a interdependência desta tríade está na formação permanente e na experiência de cada professor, sendo esses processos individuais e coletivos ao mesmo tempo.

O cenário de cuidados sanitários deslocou-nos dos espaços conhecidos de práticas educacionais e se colocaram incisivos. Patrícia Rocha, Daniela Kanashiro e Ana Karla Pereira de Miranda discutem seus sentidos no artigo Ressignificando os Estágios Obrigatórios do Curso de Letras/EaD/UFMS: os desafios impostos pela pandemia, as estratégias $e$ as possibilidades. Questões de recomendações sanitárias, planejamentos, práticas e avaliação, impuseram estudos para serem compreendidos. Dos primeiros momentos passados, coube uma avaliação dos participantes da pesquisa feita para quantificar e qualificar a formação docente em suas relações com as dificuldades que impactaram sobre a socialização profissional. Estamos em tempos de passos cautelosos, mas impregnados de coragem.

O Pibid marca um espaço de formação muito importante para a docência, que se constrói sob a perspectiva investigativa, que pode ser verificado no estudo de Talita Molina Lopes Tanes e Elias Terra Werner, intitulado Iniciação à docência: importância da construção de saberes relacionados à prática docente. A materialidade foi produzida por questionários e entrevistas semiestruturadas que levaram à construção de quatro categorias: saberes da formação profissional, saberes curriculares, saberes disciplinares e saberes experienciais. A discussão de cada uma das categorias reitera que o Pibid, pela prática docente experimentada durante a formação inicial, mostra a congruência de um currículo formativo de vivências sensíveis e marcantes para a prática profissional.

Anahy Arrieche Fazio, Valmir Heckler e Maria do Carmo Galiazzi são os autores do texto Indagação Dialógica de Gordon Wells em Processos Formativos com Professores: Interlocuções com a Comunidade Científica Internacional e discorrem sobre a perspectiva fenomenológica hermenêutica, o que se mostra da indagação dialógica de Gordon Wells em comunicações da comunidade científica internacional que envolvam processos formativos. Nesse estudo foram analisados 119 trabalhos, dos quais emergiram cinco categorias. Os aspectos que se mostram em relação aos contextos em que a indagação dialógica de Gordon Wells é integrada e fornecem pistas para que seja possível compreender o desenvolvimento profissional em um viés dialógico, social e colaborativo em ambientes com sujeitos diferentes. 
No artigo Prática educativa: reflexão do professor na perspectiva freiriana no contexto da pandemia, as autoras Ana Lúcia de Araújo Claro, Evelise Maria Labatut Portilho e Lisandra Babireski Barcia da Silva realizaram uma revisão teórica sobre a prática educativa na perspectiva de Paulo Freire no contexto da pandemia. Os resultados apontaram para a precisão de refletir acerca da prática docente, em especial diante de momentos de crise sanitária como a vivenciada na recente pandemia, que necessita de uma reflexão contínua sobre o fazer pedagógico e sobre a práxis que se materializa na articulação da teoria e prática por meio de um processo dialógico de reflexão e ação transformadora da prática educativa.

A Formação inicial de professores em uma instituição de EBPT: desafios a partir do olhar dos egressos, de autoria de Danieli Melo Zarzicki e Neiva Maria Frizon Auler, investigou a inserção dos formandos dos cursos de Licenciatura em Ciências Biológicas, Química e Matemática, dos anos de 2010 a 2014, no ambiente educacional. Os participantes da pesquisa indicaram que o Pibid, estágios curriculares e atividades de laboratório foram apontados como pontos positivos da formação. Já os aspectos negativos sinalizados foram a pouca regência em sala de aula, tardia oferta de Libras na matriz curricular e pouca importância para a Educação Especial.

O artigo de Derli Juliano Neuenfeldt, Rogério José Schuck e Isabel Pavan problematiza o corpo para a aprendizagem: Aulas Virtualizadas no Ensino Superior: ainda precisamos do corpo para ensinar e aprender? A prática docente está em problematizar a virtualização do ensino em um espaço remoto de encontro, posto que transita entre a possibilidade de renúncia ao físico e presencial. Se as práticas são o encontro físico, o teórico está para os estudos remotos? De uma busca significativa para a produção dos dados, alegramo-nos em saber que o corpo tem lugar na aprendizagem e sua ressignificação durante a pandemia de Covid-19 destaca a relação necessária com o outro e por meio dos sentidos corporais.

$\mathrm{O}$ artigo intitulado Atividade Experimental Problematizada (AEP): Discussões Pedagógicas e Didáticas de uma Asserção de Sistematização Voltada ao Ensino Experimental das Ciências, de autoria de André Luís Silva da Silva, Paulo Rogério Garcez de Moura e José Cláudio Del Pino, apresenta a Atividade Experimental Problematizada (AEP), definida por eles como uma proposta de sistematização teórico-metodológica voltada ao ensino das Ciências, nas particularidades da experimentação. Para tal, trabalham à luz da Teoria da Aprendizagem Significativa e da Epistemologia de Thomas Kuhn.

A narrativa autobiográfica apresentada por Joyce Melo Mesquita e France Fraiha-Martins intitulada Por que ensino do jeito que ensino? Reflexões de uma professora para pensar a docência em Química, traz o relato de vivências revisitadas como processo autoformativo. Experiências na escola, como aluna e professora; a solidão docente; a formação continuada e o coletivo foram as categorias eleitas para um processo reflexivo. Nos seus resultados, o texto traz três princípios formativos a saber: a escola é lugar de aprendizagem docente; o exercício de pesquisa e reflexão é indissociável da formação e da prática docente e parcerias potencializam a construção coletiva de novas práticas. 
O texto das autoras Gisele Soares Lemos Shaw e Letícia Maria de Oliveira traz o cenário da pandemia de Covid-19, quando novas formas de ensinar e aprender foram se apresentando nos cursos de formação de professores, nas universidades. Oficinas Interdisciplinares Remotas: o ensino de ciências para pessoas com transtorno do espectro autista e a busca pela inclusão é a experiência realizada com 13 licenciados em Ciências da Natureza, na disciplina acadêmica Núcleo Temático Inclusivo no Ensino de Ciências, que integram ensino, pesquisa e extensão. Alunos autistas e não autistas participaram das oficinas e, de ideias estereotipadas, as autoras perceberam a ampliação das percepções promovidas pelo processo formativo.

Os artigos de Alicia Riveiro Morales, da UPN-México, e de Carlos Moya Ureta, do Instituto Latinoamericano de Altos Estudios Sociales (Ilaes posgrados Chile), colaboradores e interlocutores de nossos estudos e pesquisas, encerram o Dossiê.

No artigo intitulado Proposta de Formação de Professores Interculturais, Alicia Riveiro Morales sintetiza os resultados de um estudo realizado no início de 2020 para conhecer necessidades e temas de interesse para uma proposta curricular de formação de professores interculturais. As informações foram coletadas com um questionário, submetido a 700 pessoas (professores em exercício, equipes de gestão, formadores de formadores, alunos do último semestre e licenciados de diferentes cursos), que propiciaram traçar uma proposta curricular flexível e aberta para incorporar conhecimentos ecológicos, ancestrais, e planetários para bem viver e cuidar o outro.

Por sua vez, Carlos Moya Ureta, no artigo Investigación Universitaria y Formación en Posgrados, chama a atenção de que a pesquisa universitária deve considerar diferentes práticas e formação de pesquisadores universitários na e da universidade. A tradição acadêmica separa o Ensino da Pesquisa como se fossem duas esferas distintas, mas que precisam ser articuladas desde o início do processo.

O convite está lançado! A reunião de artigos qualificados também são provocações para continuarem as investigações nos diferentes espaços de ensino, pesquisa e extensão para estes tempos. Boa leitura!

Editores responsáveis:

Prof. Dr. Vantoir Roberto Brancher (IFFarroupilha)

Profa. Dra. Valeska Maria Fortes de Oliveira (UFSM)

Profa. Dra. Tania Micheline Miorando (UFSM)

Profa. Dra. Keiciane Canabarro Drehmer-Marques (UFSM) 